\title{
妙用网络信息技术 优化语文线上教学
}

\author{
廖丹丹 \\ 青海师范大学 \\ DOI:10.32629/er.v3i9.3178
}

\begin{abstract}
[摘 要] 在互联网不断发展的背景下, 线上教学如今已是大势所趋, 通过分析语文线上教学的现状发现 存在学生自主学习能力不足、教师教育理念存在偏差、教师信息技术水平不高的问题,并提出了优化课 前辅导、优化课堂架构、优化课后练习这三个优化策略。

[关键词]网络信息技术; 语文; 线上教学

中图分类号: G434 文献标识码: A
\end{abstract}

近几年,网络在线学习成为了现代 教育背景下出现的一种新的学习方式, 同时也是积极响应教育部“停课不停学” 号召的有效教学手段。但是新事物的发 展前途是光明的, 道路却是曲折的, 在语 文线上教学实施的过程中应充分了解掌 握学生的实际需求, 分析研究存在的问 题, 加深对语文线上教学规律与特点的 认识, 加强师生之间的互动交流, 最大限 度地克服线上教学存在的不足, 才能有 效提升小学语文线上教学的质量, 促进 学生的全面健康发展。

\section{1 语文线上教学的现状和问题}

1.1 学生自主学习能力不足, 学习兴 趣低

习惯于传统课堂教学环境的学生, 在初接触线上学习时, 出于对新学习形 式的好奇心以及新鲜感, 会产生较高的 学习兴趣。但这样的学习兴趣是外在刺 激而生, 并不是内发型的, 因此持续时间 并不能长久, 很快就会出现倦急感。同时, 脱离了学校环境, 由家长代替教师进行 监督学习, 学生的学习自主性明显下降, 学生们首先应该明确学习是个人的事情, 是自主的活动。

由于语文学科是一个以文字这一抽 象化语言符号为载体的学科, 有时学生 仅凭自身力量是难以完全掌握全部的语 文知识内容的, 因此学生常常会在自学 过程中遇到一定的障碍。学生自主学习 能力的不足, 往往会阻碍学生语文知识
学习体验的获得, 影响学生语文学习兴 趣的提升。但有效的自主学习能够帮助 学生内化和掌握一些新知识, 并作出一 些有效思考, 这对教学的有效性也造成 了一定程度的影响。

1.2 教师教育理念存在偏差, 课堂效 率低

现代教学技术的更新, 线上教学的 实施, 对语文教师来说是巨大的挑战。作 为教学主导角色的语文教师必须意识到 传统教学与语文课程定位是相悖的, 教 师角色发生了很大的变化, 教师成为了 教学的组织者, 成为学生学习的引导者、 合作者。如果在进行线上教学的过程中, 仍是只能听到教师一个人的声音, 教学 氛围不佳, 学生参与度不高, 那么课堂效 率一定是低下的。如今的孩子, 思想非常 活跃, 他们不再能接受灌输式教学, 更欢 迎平等的探究式教学方式, 因此, 教师的 教育理念一定要及时更新, 无论是主讲 者还是主导者, 教师在课堂上都有绝对 的权威。现代化教学环境下, 教师的权威 不在于让学生怎么听, 而在于让学生怎 么做、做什么, 一定要发挥好学生的主体 性。如此, 学生不仅能够学习到书本中规 定的学习任务, 还能习得学习语文的能 力以及处理信息的能力, 从而实现语文 课堂的高效性。

1. 3教师信息技术水平不高, 资源利 用率低

现代的语文教师, 尤其是老教师, 从
传统的粉笔、黑板, 到运用计算机、网络 进行授课, 这些新知识和新技能的掌握 大多是通过自学或短期培训, 他们在心 理上一般都存在一定程度的排斥感和负 担感, 对要学习新知识和新技能, 思想上 也会有畏难和退缩情绪。教师虽然有信 息技术的利用意识, 但是实践却很少。其 实, 语文教师可以充分利用海量的网络 资源, 从中簰选出有用的部分, 进行知识 的积累与储备。但由于语文教师自身信 息技术水平的不足, 检索能力差, 构建资 源库的意识薄弱, 且对现代教学设备和 网络学习APP不够熟悉, 语文课堂仍然是 传统意义上的封闭式课堂, 大量的网络 教学资源利用率不高, 学生的学习优势 也不能得到有效发挥。

\section{2 优化语文线上教学的策略}

2. 1 优化课前辅导, 做好教学准备

课前辅导环节是课堂教学的准备环 节, 也是课堂教学的奠基环节。而让学生 们学会预习, 则是课前辅导环节的第一 步。预习就是一个让学生自读自悟的自 主学习过程。通过自主学习, 学生要掌握 自学方法, 提高语文素养, 养成自主学习 的习惯, 为终身学习打下基础。预习效果 的好坏对语文课堂目标的实现有着直接 的影响。

针对语文线上教学, 不妨利用网络 平台的优势, 让学生在预习过程中, 充分 发挥自主性, 同时也能得到教师的有效 指导, 让学生在进行对语文课文的课前 
预习时, 也能有计划、有目的地学习与思 考。教师可通过网络平台上的文件共享 功能, 将预习要求及检索到的相关教学 资料一并分享给学生, 学生也可以充分 的利用好网络资源, 自主查阅相关资料, 并在学习群中分享。这样的课前自主学 习环节, 可以营造出一种开放且多元的 学习氛围。学生可以将教师分享的拓展 资料进行收藏保存, 作为个人素材和学 习资料, 教师也可以整合学生分享的内 容进行个人资源库的构建, 教学合一。学 生在预习搜集信息查找资料的过程中, 能对信息进行辨析、取舍, 这样的学习过 程才能让学生的学习自主能力得到不断 的提升。

此外, 语文教师可以通过以往的教 学经验, 搜集网络学习资源, 制作出对语 文课堂教授内容重难点讲解的微视频, 帮助学生更好的完成课前预习。在网络 学习群中, 学生还可以提出问题, 教师在 线答疑。在课堂教学之前, 还可以通过线 上教学平台提前发布简单易统计的预习 情况调查问卷, 根据问卷反馈出的数据 结果, 适当地调整本节语文课的教学目 标和教学设计, 确保课堂教学的有效性 与针对性。

\section{2 优化课堂结构, 创设互动氛围}

传统的语文课堂结构大致为 “作者 介绍、时代背景、阅读分析、结束、复 习”这五个部分, 但实际上其中许多环节 都是线上的语文课堂应该省略的, 线上 教学不应该再照搬传统课堂中的教学模 式, 这样的教学形式不仅造成了教学环 节的重复, 也不能够吸引学生, 引起学生 的学习兴趣, 造成了课堂效率的低下。互 联网平台出现后, 这些教学环节完全可 以由学生在课前根据各自不同的实际需 要进行自主取舍, 这样就避免了浪费有 限教学时空的问题。
语文教师应在实际的线上教学过程 中创设出课堂的互动氛围, 注重和学生 进行对话, 在互动的过程中加深学生对 课文的理解。在语文课堂中教师应引导 学生提出问题, 讨论问题, 并对问题作出 解答。语文课堂应该给学生提供更多直 接参与的机会, 只有学生积极主动的参 与到学习活动中去, 学生的学习欲望变 强, 语文课堂效率才能得到提升。线上学 习可以激发学生对学习过程的控制, 集 中学生的注意力, 教师引领学生, 主动与 文本建立联系, 通过与文本的激荡, 与教 师、同学的积极合作, 深入理解掌握语文 知识, 不断提高语文核心素养, 养成好的 学习习惯。

\section{3优化课后练习, 应用灵活手段}

一堂语文课的教学成效往往体现在 学生的课后作业完成情况上, 而线上的 语文教学也不外乎如此。对于一篇语文 课文的学习, 传统语文教学课程多会采 用一段文字进行总结, 学生的课后作业 也多以书面形式进行提交, 并通过书面 作业的正确率来检验对于一节语文课学 习的吸收情况。由于线上语文教学的特 殊性, 语文教师可以通过终端向学生发 送课后作业, 学生的书面作业多以照片 或是文档的形式进行提交。因此, 语文教 师应充分利用信息技术的优势, 单项选 择题运用云课堂的自动批改功能, 对于 一些主观类题目及时运用圈划功能进行 批改，也可适当使用批注、聚焦等功能。 在线上批改课后练习不仅能够提高教师 的工作效率, 同时也能使学生们的作业 情况更具可视化, 每个学生都能看到其 他同学的作业完成情况, 能够学到其他 同学的长处, 激励学生不断进步。

线上教学还可以呈现出更加开放多 元的课后练习形式, 不仅仅局限于刻板 的书面作业, 还可以采用更多的作业展
现形式。学生的表达方式和途径应该更 加多样化, 学生可在课后通过录制一段 微视频、一段演讲录音等形式展示个人 对语文课堂主题的深刻理解, 同时也让 学生的个性化得到了发展。此外语文教 师还可以设置课后的共同作业时间, 教 师和学生一起在线上进行阅读, 在阅读 后教师可以通过截屏提问的方式对阅读 文章的片段进行学习, 这样不仅调动了 学生学习的积极性, 教师也能可对学生 的学习情况进行实时监测。

\section{3 结论}

网络信息技术所带来的变化远远超 过人们的想象, 语文线上教学也为语文 教师提供了一种新的教学可能, 这既是 尝试也是挑战。只要语文教师能够灵活 运用信息技术手段, 打破传统教育模式 的束缚, 将学习的主动权还给学生, 培养 学生的自主学习习惯, 使语文学习从传 统模式中跳脱出来, 让学生在线上学习 的过程中掌握好主动权, 将自己变为学 习的主宰, 那么语文课程的教学质量一 定能够得到提升。

\section{[参考文献]}

[1]邢玲香.网络在线学习在语文研 究性学习中的实施策略 [J].中国信息技 术教育,2009(18):84.

[2]黄森. “互联网十小学语文”的智 慧课堂模式探索[J].中国现代教育装 备,2018(12):20-23.

[3]邻永兰.基于核心素养的小学语 文研究性写作教学策略[J].新作文(语文 教学研究),2020(09):37-38.

\section{作者简介：}

廖丹丹 (1996--), 女, 汉族, 江苏盐城 人, 教育学硕士, 青海师范大学人文学院 课程与教学论专业,研究方向: 语文课程 与教学论。 